\title{
Students' Response to the Covid-19 Remote Learning Transition
}

Sandra Dunbar-Smalley

AdventHealth University, sandra.dunbar-smalley@ahu.edu

Roy Lukman

AdventHealth University, Roy.Lukman@ahu.edu

Joe Hawkins

AdventHealth University, joe.hawkins@ahu.edu

Follow this and additional works at: https://nsuworks.nova.edu/ijahsp

Part of the Higher Education Commons, and the Online and Distance Education Commons

\section{Recommended Citation}

Dunbar-Smalley S, Lukman R, Hawkins J. Students' Response to the Covid-19 Remote Learning Transition. The Internet Journal of Allied Health Sciences and Practice. 2021 Jan 01;19(3), Article 14.

This Manuscript is brought to you for free and open access by the College of Health Care Sciences at NSUWorks. It has been accepted for inclusion in Internet Journal of Allied Health Sciences and Practice by an authorized editor of NSUWorks. For more information, please contact nsuworks@nova.edu. 


\title{
Students' Response to the Covid-19 Remote Learning Transition
}

\begin{abstract}
Background: The global pandemic has created a need for several higher education institutions to transition to emergency remote learning. Students and faculty have experienced a significant disruption to their daily academic routines. It is critical to understand the perceptions of students in relationship to their learning experiences and ability to effectively manage the new and changing learning environment and expectations. This study sought to understand the students' response to the transition to remote learning, as a necessary strategy for managing learning during the pandemic. Methods: A 15-item electronic survey was provided to approximately 1600 students at a private faith-based university in Central Florida, United States. Results: The response rate of $38 \%$ indicated primary positive responses to the transition, with significant differences of comfort level of remote learning and perceptions of faculty readiness, when analyzed between undergraduate and graduate students.
\end{abstract}

Author Bio(s)

Sandra Dunbar-Smalley DPA, OTR/L, FAOTA

Sandra is currently the Provost and Chief Academic Officer at AdventHealth University. She is the former Assistant Dean of Professional Development at Nova Southeastern University. Sandra is a licensed Occupational Therapist and also has a doctorate in Public Administration.

Roy Lukman, PhD

Dr. Lukman has been the Director of Academic Affairs for AdventHealth's Graduate Medical Education Department, as well as holding positions as the Director of Research and also the Associate Director for Behavioral Medicine since 1988. In 2010, he joined AdventHealth University as the Director of Institutional Effectiveness. He currently serves as the Research Consultant for the University.

Joe Hawkins, M.S.Ed., CNMT

Joe is the Director of Institutional Effectiveness and Accreditation at AdventHealth University. Prior to that, he was as an Associate Professor and the founding director of the Nuclear Medicine Technology program at AHU. He still serves as an adjunct professor in the Imaging Sciences Department.

\section{Acknowledgements}

Acknowledgement: The authors thank Mary Rickelman, MLIS, AHIP - Reference, Liaison, \& Cataloging Librarian at the R.A. Williams at AdventHealth University, for her assistance in literature mining. 


\title{
1IJAHSP \\ The Internet Joumnal of Allied Health Sciences and Practice \\ Vol. 19 No. 3 ISSN 1540-580X
}

\section{Students' Initial Response to the Covid-19 Remote Learning Transition:}

\section{A Pilot Study}

\author{
Sandra Dunbar-Smalley \\ Roy Lukman \\ Joe Hawkins
}

AdventHealth University

United States

\begin{abstract}
Background: The global pandemic has created a need for several higher education institutions to transition to emergency remote learning. Students and faculty have experienced a significant disruption to their daily academic routines. It is critical to understand the perceptions of students in relationship to their learning experiences and their ability to effectively manage the changing learning environment and expectations. This study sought to understand the students' response to the transition to remote learning, as a necessary strategy for managing learning during the pandemic. Methods: A 15-item electronic survey was provided to approximately 1200 students at a private faith-based university in Central Florida, United States, with a satellite campus in Denver, Colorado. Results: The response rate of $38 \%$ indicated primary positive responses to the transition, with significant differences of comfort level of remote learning and perceptions of faculty readiness, when analyzed between undergraduate and graduate students.
\end{abstract}

Keywords: remote learning, COVID-19 response, distance education 


\section{BACKGROUND}

The academic year of 2019-2020 will long be remembered as one of the most disruptive, yet innovative, periods in higher education history. With the increasing spread of the coronavirus (COVID-19) between December, 2019 and March, 2020, the global devastation had already resulted in over 700,000 deaths. ${ }^{1}$ Not only does the pandemic continue to have an overwhelming impact on the health, social and economic well-being of most countries at the time of this writing, but it is also significantly changing the priorities of educational institutions. Estimates of student numbers affected by school closures, as a result of the pandemic, range between $80-91 \%$ worldwide. ${ }^{1,2}$ This staggering statistic provides a means of understanding the toll of the impact of COVID-19 on academic entities from elementary levels to higher education.

One of the most significant responses to the pandemic by higher education institutions has been the transition to emergency remote learning. This differs from what is traditionally known as online learning. Online learning is defined as learning experiences that occur synchronously or asynchronously using a variety of technology tools with internet access. This borderless opportunity to learn in online spaces, is now based on sound pedagogy, years of research evidence, critical standards, and thorough training, when implemented effectively. 2,3,4 Emergency remote learning contrasts from these well planned approaches, and is defined as a temporary shift to a distance learning mode, due to a particular crisis or set of circumstances which require a quick response. ${ }^{4}$

The abrupt or accelerated movement to emergency remote learning has been met with varying faculty responses'. It has also required a rapid shift for students who are unfamiliar with the remote learning expectations and methods. Some universities were well prepared with learning management systems in place, and at least some online courses or programs already provided. In addition, some institutions had online curriculum designers, specialists, and technicians, to ramp up efforts across more programs. Other universities did not have these elements and continue to lack adequate human resources and a strong infrastructure to support online teaching/learning pursuits. These factors have led to even more student concern and anxiety, in relationship to the future of their learning. ${ }^{5}$

Because China was affected the most by COVID-19 at the earliest stages of the pandemic, there are many insights to be gained from the experiences of Chinese universities. 2,6 The Ministry of Education initiated a program focused on "disrupted classes, but undisrupted learning." This was proceeded by specific guidelines related to the management of online teaching in higher education institutions during the pandemic. ${ }^{2,7}$ This effort attempted to ensure standards for quality, recognition of workload consideration, and student-centric approaches, including active engagement in self-directed learning for optimal online experiences. ${ }^{2}$ The Beijing Normal University furthered their efforts for emergency remote learning by strategically augmenting the governmental guidelines. This included providing options in online education platforms, creating a special team for faculty support and training, as well as increasing the number of teaching assistants for online classes. Evaluation strategies were also implemented by collecting data on the online courses, including student readiness for the shift. The Peking University implemented several robust strategies for effectively moving to remote learning. This involved intentionally using teaching techniques that required active participation from students, so that they would not be inclined to avoid attending their online classes. ${ }^{6}$ Both of these universities recognized the significance of student needs, including adequately supporting their social-emotional and learning aspects in the transition.

Blankstein, Frederick, and Wolff-Eisenberg created one of the first comprehensive pandemic student experience surveys that has been done to date, with 21 colleges and universities participating in the United States. ${ }^{8}$ The findings from over 15,000 students' responses was published after the deployment and analyses of the survey in this report, but provides an extensive view of student perceptions in much broader areas. Students in that study identified a need for more information from academic support services. The students who were surveyed were also challenged by trying to find a balance between work, school and home life, particularly for study and schoolwork time in the home setting. Students identified physical and mental health challenges that increased due to the pandemic, including food insecurity. This study offered several insights into a broader spectrum of needs for students during this global pandemic era.

\section{CONTEXT of PILOT STUDY}

AdventHealth University (AHU) is a healthcare-oriented university, started in 1992, and affiliated with the large AdventHealth healthcare organization. In 2001, AHU became an early adopter of online education and continues to have well recognized online programs, including healthcare administration and family nurse practitioner degrees on the master's level. However, other university professional programs were not traditionally $100 \%$ online, such as occupational and physical therapy. Emergency remote learning became necessary in these and other graduate programs, as well as undergraduate studies. Current accreditation standards and guidelines, as well as common practices in preparing healthcare professionals, heavily influenced the face-to-face nature of graduate programs such as Occupational and Physical Therapy prior to the pandemic. Both programs are augmented with online platforms for document submission and a variety of teacher/student connections, but the primary mode of instruction 
delivery was face-to-face. The undergraduate programs were primarily based on the traditional model and students commuted to campus, with some residing in nearby dormitories. Since most of the graduate programs are very cohort driven, it was important to evaluate if there were differences between these students and those who had a more individualized orientation to general studies in the undergraduate cluster. The move to remote learning was necessary for the more traditionally taught courses and programs, in order to ensure the safety of university employees and students with the emergent pandemic.

\section{PURPOSE}

The purpose of this pilot study was to assess the perceptions of students regarding the transition to remote learning at a faithbased higher education institution in the southeast United States. In an effort to understand how best to meet the students' needs in this rapid transition, and to assess how the transition was evolving after one month of the emergency remote learning, a survey was developed by the AHU Institutional Effectiveness Director and the former Research Director (co-authors). In the interest of time and to address the needs quickly, a limited number of other surveys that were available were reviewed for question construction. However, the university administration provided the primary feedback before deployment. The specific objectives of the study were to:

1. Expeditiously understand students' perceptions of the university's management of the transition to remote learning

2. Understand instructor readiness for the transition from the lens of students

3. Understand the level of support that students experienced in the transition

4. Identify if differences existed between undergraduate and graduate student perceptions

5. Identify if differences existed between experienced and first-time remote learners

The lessons gained from this pilot study at one university may enlighten others who are grappling with the management of the immediate and long-term impact of the pandemic on higher education.

\section{METHODS}

\section{Data collection procedures}

The survey and methods were reviewed by a university research officer and deemed to be an academic quality improvement activity, negating the necessity to advance to full IRB processes. A letter from the university President and the Provost was initially emailed to the students, informing them of the upcoming survey and its purpose. It also included the assurance for anonymity and confidentiality of data management and reporting. A web-based survey was then distributed for a two-week period with e-mail reminders every three days.

\section{Instrument}

A review of current literature identifying key areas of concern in transitioning to remote learning during the pandemic was completed with the assistance of a university librarian. This unique situation resulted in a paucity of specific literature related to transitioning to emergency remote learning during a pandemic at the time of this initial writing, but the authors did utilize information from literature related to planned transitions from face-to-face to online learning, which proved useful for question construction. A review of the survey was completed by the university President's Council for alignment with intended goals of understanding students' perspective. With the President's Council feedback and approval, a 15-item mixed method survey was completed for distribution.

\section{Sample}

A total of 1199 students were transitioned from campus to remote learning environment. After a two-week period of data collection, 458 students responded, yielding a response rate of $38.2 \%$.

\section{Demographics}

The demographic table below, comparing the distributions of gender, ethnicity, and age, demonstrated that the sample distributions are closely aligned with the population of the students with no statistical differences indicated.

TABLE 1. Distribution Comparisons

\begin{tabular}{|l|l|}
\hline Demographic & $p$ \\
\hline Gender & 0.1573 \\
\hline Ethnicity & 0.3492 \\
\hline Age & 0.2930 \\
\hline
\end{tabular}

The respondents represented all academic programs that were displaced to remote learning due to COVID-19, as shown in Table 2. 
TABLE 2. Program Distribution

\begin{tabular}{|l|c|c|c|}
\hline \multicolumn{1}{|c|}{ Program } & Level $^{*}$ & Number of students & Percentage \\
\hline Nursing & UG & 182 & $39.7 \%$ \\
\hline Physician Assistant & G & 37 & $8.1 \%$ \\
\hline Diagnostic Medical Sonography & UG & 34 & $7.4 \%$ \\
\hline Biomedical Sciences & UG & 32 & $7.0 \%$ \\
\hline Physical Therapy & G & 31 & $6.8 \%$ \\
\hline Nurse Anesthesia & G & 26 & $5.7 \%$ \\
\hline Radiography & UG & 23 & $5.0 \%$ \\
\hline Other/did not specify & & 20 & $4.4 \%$ \\
\hline Health Sciences (BS) & UG & 19 & $4.2 \%$ \\
\hline Occupational Therapy & G & 17 & $3.7 \%$ \\
\hline Occupational Therapy Assistant & UG & 13 & $2.8 \%$ \\
\hline Healthcare Administration & UG & 8 & $1.8 \%$ \\
\hline Nuclear Medicine Technology & UG & 7 & $1.5 \%$ \\
\hline Healthcare Administration & G & 6 & $1.3 \%$ \\
\hline Health Sciences (AS) & UG & 3 & $0.7 \%$ \\
\hline
\end{tabular}

${ }^{*} \mathrm{UG}=$ undergraduate; $\mathrm{G}=$ graduate

For the quantitative survey methods, data were compiled for group aggregate reports using descriptive statistics for the Likert items. Summary analysis was done for the open-ended question items. Distributions of responses on the Likert items were further compared between first time vs. experienced remote learners, and undergraduate vs. graduate students using the non-parametric chi-square goodness of fit analysis. This was used to evaluate any possible differences that may exist between the categorical variables.

\section{RESULTS AND ANALYSIS}

The overall results for each of the Likert scale items are shown below:

TABLE 3. Survey Results

\begin{tabular}{|l|c|c|c|c|}
\hline \multicolumn{1}{|c|}{ Items } & Strongly Agree & Agree & Disagree & Strongly Disagree \\
\hline $\begin{array}{l}\text { AHU administration has managed the transition } \\
\text { from on-campus to remote learning well }\end{array}$ & $28.9 \%$ & $59.2 \%$ & $7.6 \%$ & $4.4 \%$ \\
\hline AHU updates on COVID-19 have been helpful & $28.2 \%$ & $60.3 \%$ & $8.5 \%$ & $3.0 \%$ \\
\hline $\begin{array}{l}\text { I have felt AHU's care and concern for me in this } \\
\text { transition }\end{array}$ & $34.9 \%$ & $52.1 \%$ & $9.4 \%$ & $3.7 \%$ \\
\hline $\begin{array}{l}\text { I am comfortable in the remote learning } \\
\text { environment }\end{array}$ & $24.3 \%$ & $44.0 \%$ & $21.6 \%$ & $10.1 \%$ \\
\hline $\begin{array}{l}\text { My instructors are skilled in managing the remote } \\
\text { learning activities }\end{array}$ & $24.5 \%$ & $56.9 \%$ & $14.2 \%$ & $4.4 \%$ \\
\hline $\begin{array}{l}\text { My remote learning assignments are consistent } \\
\text { with the campus experience }\end{array}$ & $19.0 \%$ & $46.6 \%$ & $26.2 \%$ & $8.3 \%$ \\
\hline $\begin{array}{l}\text { My instructors have been supportive and } \\
\text { responsive to me during the transition period }\end{array}$ & $44.3 \%$ & $49.1 \%$ & $4.4 \%$ & $2.3 \%$ \\
\hline $\begin{array}{l}\text { I still feel connected to AHU through the planned } \\
\text { remote activities }\end{array}$ & $21.3 \%$ & $51.8 \%$ & $21.1 \%$ & $5.7 \%$ \\
\hline $\begin{array}{l}\text { I feel the spiritual support from AHU during this } \\
\text { time of transition }\end{array}$ & $31.4 \%$ & $56.9 \%$ & $8.3 \%$ & $3.4 \%$ \\
\hline
\end{tabular}


Visual inspection of the distribution of responses in Table 3 indicated that students' responses are primarily positive. The distribution responses were further analyzed by rank ordering the items from highest percentages of responses in the positive categories (Strongly Agree and Agree), to the lowest percentages of the same categories.

TABLE 4. Rank ordered according to percentages of positive categories - (Strongly Agree and Agree)

\begin{tabular}{|l|c|}
\hline \multicolumn{1}{|c|}{ Items } & Percentages \\
\hline $\begin{array}{l}\text { My instructors have been supportive and } \\
\text { responsive to me during the transition period }\end{array}$ & $93.4 \%$ \\
\hline AHU updates on COVID-19 have been helpful & $88.5 \%$ \\
\hline $\begin{array}{l}\text { I feel the spiritual support from AHU during this } \\
\text { time of transition }\end{array}$ & $88.3 \%$ \\
\hline $\begin{array}{l}\text { AHU administration has managed the transition } \\
\text { from on-campus to remote learning well }\end{array}$ & $88.1 \%$ \\
\hline $\begin{array}{l}\text { I have felt AHU's care and concern for me in this } \\
\text { transition }\end{array}$ & $87.0 \%$ \\
\hline $\begin{array}{l}\text { My instructors are skilled in managing the remote } \\
\text { learning activities }\end{array}$ & $81.4 \%$ \\
\hline $\begin{array}{l}\text { I still feel connected to AHU through the planned } \\
\text { remote activities }\end{array}$ & $73.1 \%$ \\
\hline $\begin{array}{l}\text { I am comfortable in the remote learning } \\
\text { environment }\end{array}$ & $68.3 \%$ \\
\hline $\begin{array}{l}\text { My remote learning assignments are consistent } \\
\text { with the campus experience }\end{array}$ & $65.6 \%$ \\
\hline
\end{tabular}

It was clearly indicated that there was a difference with three items showing percentages below $80 \%$ :

- I still feel connected to AHU through the planned remote activities

- I am comfortable in the remote learning environment

- My remote learning assignments are consistent with the campus experience

These three areas identified a disconnection in not just geographical aspects, but perceptions of differences in the learning experiences and discomfort with the changes. This was further substantiated in the qualitative data with comments reflecting how different the assignments were (more written work), and many recorded lectures integrated into the remote teaching. This substantiates the difference between remote and traditional online teaching, with quick processes developed to ensure some level of teaching/learning was available while instructors made this immediate and necessary shift.

The distribution of responses for the Likert items were further evaluated by two comparisons:

- First time and experienced remote/online learners

- Undergraduate versus graduate students

\section{First-time Experience}

Further comparisons were conducted by analyzing the distribution of ratings regarding previous experience with remote learning.

Table 5. Comparison of Responses Based on Previous Experience

\begin{tabular}{|l|c|c|c|c|c|c|}
\hline \multicolumn{1}{|c|}{ Item } & Group & $\begin{array}{c}\text { Strongly } \\
\text { Agree }\end{array}$ & Agree & Disagree & $\begin{array}{c}\text { Strongly } \\
\text { Disagree }\end{array}$ & $\mathrm{p}$ \\
\hline \multirow{2}{*}{$\begin{array}{l}\text { AHU administration has managed the } \\
\text { transition from on-campus to remote } \\
\text { learning well }\end{array}$} & First-time & $26.8 \%$ & $59.8 \%$ & $8.7 \%$ & $4.7 \%$ & \multirow{2}{*}{0.58} \\
\cline { 2 - 6 } $\begin{array}{l}\text { AHU updates on COVID-19 have been } \\
\text { helpful }\end{array}$ & Experienced & $32.4 \%$ & $58.0 \%$ & $5.7 \%$ & $4.0 \%$ & \\
\hline & First-time & $25.2 \%$ & $65.4 \%$ & $6.7 \%$ & $2.8 \%$ & \multirow{2}{*}{0.07} \\
\cline { 2 - 6 } & Experienced & $32.4 \%$ & $52.8 \%$ & $11.4 \%$ & $3.4 \%$ & \\
\hline & First-time & $33.5 \%$ & $53.9 \%$ & $8.7 \%$ & $3.9 \%$ & 0.90 \\
\hline
\end{tabular}




\begin{tabular}{|l|c|c|c|c|c|c|}
\hline \multirow{2}{*}{$\begin{array}{l}\text { I have felt AHU's care and concern for me } \\
\text { in this transition }\end{array}$} & Experienced & $35.8 \%$ & $50.6 \%$ & $10.2 \%$ & $3.4 \%$ & \\
\hline \multirow{2}{*}{$\begin{array}{l}\text { I am comfortable in the remote learning } \\
\text { environment }\end{array}$} & First-time & $19.3 \%$ & $43.3 \%$ & $24.4 \%$ & $13.0 \%$ & \multirow{2}{*}{$0.00^{*}$} \\
\cline { 2 - 6 } & Experienced & $30.7 \%$ & $45.5 \%$ & $17.6 \%$ & $6.3 \%$ & \\
\hline \multirow{2}{*}{$\begin{array}{l}\text { My instructors are skilled in managing the } \\
\text { remote learning activities }\end{array}$} & First-time & $19.7 \%$ & $59.1 \%$ & $16.5 \%$ & $4.7 \%$ & \multirow{2}{*}{$0.03^{*}$} \\
\cline { 2 - 6 } & Experienced & $31.8 \%$ & $53.4 \%$ & $10.8 \%$ & $4.0 \%$ & \\
\hline \multirow{2}{*}{$\begin{array}{l}\text { My remote learning assignments are } \\
\text { consistent with the campus experience }\end{array}$} & First-time & $14.6 \%$ & $46.5 \%$ & $29.5 \%$ & $9.4 \%$ & \multirow{2}{*}{$0.02^{*}$} \\
\cline { 1 - 5 } $\begin{array}{l}\text { My instructors have been supportive and } \\
\text { responsive to me during the transition } \\
\text { period }\end{array}$ & Experienced & $25.6 \%$ & $46.6 \%$ & $21.0 \%$ & $6.8 \%$ & \\
\hline \multirow{2}{*}{$\begin{array}{l}\text { I still feel connected to AHU through the } \\
\text { planned remote activities }\end{array}$} & First-time & $43.7 \%$ & $49.6 \%$ & $4.3 \%$ & $2.4 \%$ & \multirow{2}{*}{0.99} \\
\cline { 2 - 6 } & Experienced & $44.9 \%$ & $48.3 \%$ & $4.5 \%$ & $2.3 \%$ & \\
\hline \multirow{2}{*}{$\begin{array}{l}\text { I feel the spiritual support from AHU } \\
\text { during this time of transition }\end{array}$} & Experienced & $25.0 \%$ & $46.0 \%$ & $21.6 \%$ & $7.4 \%$ & \multirow{2}{*}{0.15} \\
\cline { 2 - 6 } & First-time & $28.0 \%$ & $59.1 \%$ & $9.4 \%$ & $3.5 \%$ & \multirow{2}{*}{0.42} \\
\hline
\end{tabular}

${ }^{*}$ Statistically significant at $p \leq 0.05$.

The analysis to compare the distribution of ratings between the two groups indicated that three items achieved statistical significance $(p \leq .05)$. There was a greater proportion of first-time students who gave lower ratings than students experienced with remote learning in the following three items:

- I am comfortable in the remote learning environment $(p=0.00)$.

- My instructors are skilled in managing the remote learning activities $(p=0.03)$.

- My remote learning assignments are consistent with the campus experience $(p=0.02)$.

This difference between first-time online teaching/learning students and those more experienced students indicated a need to further understand how to better prepare students for this experience, even in an immediate situation. It is also questioned if instructors were as ill-prepared or if students who had not had these experiences prior, would have less satisfaction based on the change to their learning processes.

\section{Academic Level}

Further comparisons were conducted by analyzing the distribution of ratings between undergraduate and graduate students for each item.

Table 6. Comparison of Responses Between Graduate and Undergraduate Students

\begin{tabular}{|c|c|c|c|c|c|c|}
\hline Item & Group & $\begin{array}{l}\text { Strongly } \\
\text { Agree }\end{array}$ & Agree & Disagree & $\begin{array}{l}\text { Strongly } \\
\text { Disagree }\end{array}$ & $p$ \\
\hline \multirow{2}{*}{$\begin{array}{l}\text { AHU administration has managed the } \\
\text { transition from on-campus to remote } \\
\text { learning well }\end{array}$} & First-time & $26.1 \%$ & $61.3 \%$ & $8.4 \%$ & $4.2 \%$ & \multirow{2}{*}{0.86} \\
\hline & Experienced & $29.9 \%$ & $58.6 \%$ & $7.0 \%$ & $4.5 \%$ & \\
\hline \multirow{2}{*}{$\begin{array}{l}\text { AHU updates on COVID-19 have been } \\
\text { helpful }\end{array}$} & First-time & $23.5 \%$ & $68.1 \%$ & $4.2 \%$ & $4.2 \%$ & \multirow{2}{*}{$0.05^{*}$} \\
\hline & Experienced & $29.9 \%$ & $57.3 \%$ & $10.2 \%$ & $2.5 \%$ & \\
\hline \multirow{3}{*}{$\begin{array}{l}\text { I have felt AHU's care and concern for me } \\
\text { in this transition }\end{array}$} & First-time & $35.3 \%$ & $55.5 \%$ & $7.6 \%$ & $1.7 \%$ & \multirow{2}{*}{0.44} \\
\hline & Experienced & $34.4 \%$ & $51.0 \%$ & $10.2 \%$ & $4.5 \%$ & \\
\hline & First-time & $22.7 \%$ & $45.4 \%$ & $22.7 \%$ & $9.2 \%$ & 0.93 \\
\hline
\end{tabular}




\begin{tabular}{|l|c|c|c|c|c|c|}
\hline \multirow{2}{*}{$\begin{array}{l}\text { I am comfortable in the remote learning } \\
\text { environment }\end{array}$} & Experienced & $24.8 \%$ & $43.6 \%$ & $21.0 \%$ & $10.5 \%$ & \\
\hline \multirow{2}{*}{$\begin{array}{l}\text { My instructors are skilled in managing the } \\
\text { remote learning activities }\end{array}$} & First-time & $21.0 \%$ & $56.3 \%$ & $21.0 \%$ & $1.7 \%$ & \multirow{2}{*}{$0.03^{*}$} \\
\cline { 2 - 6 } & Experienced & $26.1 \%$ & $56.7 \%$ & $11.8 \%$ & $5.4 \%$ & \\
\hline \multirow{2}{*}{$\begin{array}{l}\text { My remote learning assignments are } \\
\text { consistent with the campus experience }\end{array}$} & First-time & $15.1 \%$ & $42.0 \%$ & $34.5 \%$ & $8.4 \%$ & \multirow{2}{*}{0.09} \\
\cline { 2 - 6 } $\begin{array}{l}\text { My instructors have been supportive and } \\
\text { responsive to me during the transition } \\
\text { period }\end{array}$ & Experienced & $20.4 \%$ & $48.4 \%$ & $22.9 \%$ & $8.3 \%$ & \\
\hline \multirow{2}{*}{$\begin{array}{l}\text { I still feel connected to AHU through the } \\
\text { planned remote activities }\end{array}$} & Experienced & $43.3 \%$ & $49.0 \%$ & $5.4 \%$ & $2.2 \%$ & \multirow{2}{*}{0.41} \\
\cline { 2 - 6 } & First-time & $21.0 \%$ & $60.5 \%$ & $17.6 \%$ & $0.8 \%$ & \multirow{2}{*}{$0.02^{*}$} \\
\cline { 2 - 6 } $\begin{array}{l}\text { I feel the spiritual support from AHU } \\
\text { during this time of transition }\end{array}$ & Experienced & $21.3 \%$ & $48.7 \%$ & $22.3 \%$ & $7.6 \%$ & \\
\hline & First-time & $34.5 \%$ & $58.8 \%$ & $6.7 \%$ & $0.0 \%$ & \multirow{2}{*}{0.08} \\
\hline
\end{tabular}

${ }^{*}$ Statistically significant at $p \leq 0.05$

The analysis to compare the distribution of ratings between the two groups indicated that three items achieved statistical significance $(p \leq .05)$. The results indicated that there is a greater proportion of undergraduate students who gave lower ratings than graduate students in the following two items:

- $\quad$ AHU updates on COVID-19 have been helpful $(p=0.05)$.

- I still feel connected to AHU through the planned remote activities $(p=0.02)$.

Conversely, graduate students gave lower ratings than undergraduate students in the following item:

- My instructors are skilled in managing the remote learning activities $(p=0.03)$.

\section{Qualitative Results}

The survey had one open-ended question on the survey for students to provide additional comments about how their experiences with remote learning can be improved. The most common responses, related to descriptive frequency counts, included the following:

- Cost

- Students commented that they paid program and lab fees and classes were switched to remote learning.

- Tuition should be decreased since all instruction was switched to remote delivery.

- Loss of clinical education and hands-on training

- Students expressed concern about how they will learn clinical skills without hands-on experiences

- Students were concerned about how the loss of clinical education would affect their program completion and eligibility for licensing exams.

- Students suggested implementing small group experiences that can be done on campus.

- Classes

- Students wanted more clarity on expectations for each class.

- Students wanted classes to continue to meet remotely at their scheduled times.

- Communication

- Students mentioned the need for more frequent communication from instructors and the university.

- Students wanted an answer even if the answer was "we don't know".

- $\quad$ Stress

- Students expressed concerns about personal finances, family, home life, and their future.

- Positives

- Students were thankful for the support from faculty and staff.

- Students mentioned that there was clarity in the communication from the university and their instructors.

- Students were pleased with the amount of communication from the university.

These qualitative results further substantiated the quantitative data by providing examples and evidence of "discomfort." The students expressed a need for better communication and clarity on assignments. Expectations for instructor preparedness and 
improved online teaching skills were also apparent. Conversely, there were many comments about the students' gratitude for the support of instructors, as well as the university administration, with acknowledgement of the stressful times.

\section{DISCUSSION}

The rapid nature of the transition from face-to-face to remote learning certainly posed a number of challenges for students. Aligned with lessons in the literature about planned transitions, the students did identify a preference for the face-to-face environment in some comments, a lack of opportunity to interface directly with peers and faculty, as well as an adjustment to varying technology. Gloria and Uttal identified that students are technologically diverse, so considerations for a continuum of training should be made, in addition to having the access to instructional designers and trained online faculty. ${ }^{9}$ Considerable time for planning was also recommended, which poses one of the most significant limitations in an emergency remote situation created by the pandemic. The Beijing Normal University strategy of providing rapid teacher training, even in the emergency situation, proved equally valuable in the efforts at AdventHealth University, as evidenced by students' acknowledgement of the efforts to support their learning in quantitative and qualitative data.

There is literature that supports similar types of student perceptions in natural disaster situations. Simms, Kusenbach, and Tobin, indicated that students in natural disasters experience distress, with a feeling of disconnection from what is familiar to them. ${ }^{10}$ Yet, the authors also describe a balance of vulnerability and resilience that students demonstrate in these types of unexpected situations. This type of balance was clearly identified in the students' comments in the current study with their identification of problems yet expressing gratitude for support and institutional planning that kept their classes going. A striking difference in the natural disaster description in the Simms, Kusenbach, and Tubin article is that students were assessed regarding their preparedness, which one can easily do for a hurricane. There is a myriad of resources for this type of natural disaster preparedness. However, the pandemic posed a very unique situation that could not be perceived from a preparedness angle.

Students were primarily positive in their responses, further demonstrating the resiliency aspect, with differences noted in comfort levels between experienced and novice online learners. Novice online learners in this environment indicated less comfort. Survey respondents included students who had taken online courses as part of their curriculum, so they were already familiar with the navigation of the online platform (Canvas). By having this level of previous exposure, it appears that it made a difference in their ability to transition with greater ease. Students who had not had the online learning experience prior to the rapid shift, indicated in their comments that they missed the face-to-face connections, and they felt a sense of disconnection, indicating this same sense of vulnerability described by Simms, Kusenbach, and Tobin. ${ }^{10}$ In addition, they shared that they didn't feel that they were learning as effectively, so this may have influenced their limited "comfort."

Other differences were noted between graduate and undergraduate respondents, with graduate respondents viewing some instructors as less prepared or not as skilled in the online arena, for example. However, more undergraduate students responded to the survey, so future plans to survey will attempt to get more graduate respondents. Another notable difference was the indication that the remote environment did not offer the same opportunity for the type of assignments. Some students commented that the assignments changed abruptly and were increased, to possibly make up for lost face-to-face opportunities.

This study further reinforced that it is critical to glean the student perspectives in the transition from face-to-face to remote learning, in order to intentionally address best practices for online teaching and learning and ensure appropriate supports. Although students were generally positive and adaptive during this process, with even the majority identifying a sense of spiritual support, there are many ways to continue to improve the experiences for optimal learning outcomes. Qualitative data did provide some important feedback for enhancing the processes. The University has now mandated a series of online training modules for faculty to be done over a two-month period, in addition to considering development of a student training module. A follow up student survey will also be deployed to compare to the initial results, as well as add mental health aspects that were not addressed in the first survey.

Blankstein, Frederick, and Wolff-Eisenberg clearly identify other aspects to consider in student life in the transitions created by the pandemic , and a follow up survey will expand to ensure that social-emotional well-being is considered. ${ }^{8}$ The content of this other study will form evidence to create additional questions, since a study limitation was the lack of model questions in this situation, due to the emergent nature of the pandemic. In addition, other typical pilot activities were not conducted to gauge student' concerns to guide the survey construction. Other limitations include a need to disaggregate the data further to understand if there are differences between the various socio-economic and ethnic background groups, as well as differences between our main campus and satellite campus students. Some of these elements did prove to be significant in the Blankstein, Frederick, and Wolff-Eisenberg study. ${ }^{8}$

(C) The Internet Journal of Allied Health Sciences and Practice, 2021 
Although a $38.2 \%$ response rate is commonly considered to be acceptable, an increased response rate may enable a broader perspective of students' experiences. Nursing, as the largest program with over 500 students, had the most respondents. This was not surprising given the enrollment numbers, however they also provided many qualitative statements about their experiences and how their learning could be improved with changes to course formatting and assignment adjustment, for example. Many students across the disciplines indicated how much they appreciated the university efforts to keep them safe and relayed that they felt their professors were doing the best that they could, considering the rapid shift to remote learning. The survey was distributed at what may have been perceived as a high stress time near the beginning of the increasing impact of COVID-19. Students were dealing with many pressures, including moving and trying to adapt to studying from home environments. The qualitative responses also indicated these multiple stressors, and this could have impacted the limited responsivity from other students. In addition, the qualitative data that was received could be better understood if rigorously assessed beyond a summative analysis. This limitation warrants a more robust approach, with a future goal of more formal qualitative analysis. This is also a strong recommendation for future studies in this area at other institutions of higher education.

Additional research is also needed to assess more specific areas of faculty skill development and need. It is questioned whether instructors needed to provide better organization, improve social engagement, or enhance other aspects of online teaching/learning. This breakdown is needed to effectively assess readiness for this type of transition. In addition, "comfort" may need to be defined more specifically to evaluate the areas that students deem easy for them to adjust to, versus more challenging. A more robust effort is needed to compare students' perceptions with faculty perceptions. Although functioning in a remote environment, it may be beneficial to conduct some synchronous forums with faculty and students together to openly discuss the barriers and supports for optimal remote engagement. A Town Hall (open forum for informal dialogue) conducted by administration after the survey results were completed proved to be a very helpful session on hearing firsthand the various students' perceptions. Creating more opportunities for qualitative data collection for students and faculty are warranted, recognizing the significant benefits of the Town Hall. Students readily and openly shared their challenges, as well as suggestions, for improvements in remote learning. Strategies to train faculty to transition to a new platform continue to be developed and implemented; however, assessing their overall needs and effectiveness in improving students' success are essential. In addition, assessing faculty members' needs for not just academic course preparation support, but general social-emotional support is also becoming evident as the pandemic continues and there is evidence of high stress levels. Faculty and staff members alike continue to demonstrate a high level of adaptation and problem-solving during these challenging times.

\section{CONCLUSION}

Efforts to meet the needs of higher education during a pandemic remain an ongoing challenge, but this unusual situation also created opportunities for positive changes. The faculty are unified and committed in working collaboratively for a more studentcentric approach, with some indicating increasing comfort in the online teaching environment since the pandemic. The degree of innovation with remote simulation and creative online active learning strategies has been impressive. Although some faculty continue to need support for envisioning the possibilities for student engagement, the virtual campus quickly mobilized and remains resilient during these most unusual times. Ongoing research efforts are needed to continue to understand students' and faculty members' perspectives, leading to important change for best practices in emergency remote and online teaching/learning.

\section{REFERENCES}

1. Sahu P. Closure of universities due to coronavirus disease 2019 (COVID-19): Impact on education and mental health of students and academic staff. Cureus, April, 202012 (4). Doi.10.7759/cureus.7541

2. Zhu X \& Liu J. Education in and after covid-19: Immediate responses and long-term visions. Postdigital Science and Education, April, 2020 doi.org/10.1007/s42438-020-00126-3

3. Singh V \& Thurman A. How many ways can we define online learning? A systematic literature review of definitions of online learning (1988-2018). American Journal of Distance Education. 201933 (4) 289-306. doi.org/10.1080/08923647.2019.1663082

4. Hodges C, Moore S, Lockee B, Trust T, Bond A. The difference between emergency remote teaching and online learning. March 27, 2020. Retrieved on May 29, 2020 from https://er.educause.edu/articles/2020/3/the0differencebetween-emergency-remote-teaching-and-online-learning.

5. Daniel SJ. Education and the COVID-19 pandemic. Prospects April, 2020. doi.org/10.1007/s11125-020-09464-3

6. Bao W. COVID-19 and online teaching in higher education: A case study of Peking University. Human Behavior \& Emerging Technology. 2020;2:113-115. https://doi.org/10.1002/hbe2.191 
7. Ministry of Education of P.R. China. Guidance on the organization and management of online teaching in the higher education institutions during epidemic prevention and control period. 2020; Retrieved on April 15, 2020. http://www.moe.gov.cniyb_xwfb/gzdt_gzdt/s5987/202002/t20200205_418131.html.

8. Blankstein M, Frederick JK, Wolff-Eisenberg C Student experiences during the pandemic pivot. Ithaka $S+R$. Retrieved 25 June 2020. Web. 29 June 2020. https://doi.org/10.18665/sr.313461

9. Gloria AM \& Uttal L. Conceptual Considerations in Moving from Face-to-Face to Online Teaching. International Journal on E-Learning, 2020;19(2), 139-159. Waynesville, NC USA: Association for the Advancement of Computing in Education (AACE). Retrieved May 30, 2020 from https://www.learntechlib.org/primary/p/184150/.

10. Simms, Kusenbach M, Tobin G. Equally unprepared: Assessing the hurricane vulnerability of undergraduate students. Weather, Climate and Society 2020:5 (3) https://doi.org/10.1175/WCAS-D-12-00056.1 